\title{
Characterization of ultrafine particle number concentration and new particle formation in an urban environment of Taipei, Taiwan
}

\author{
H. C. Cheung, C. C.-K. Chou, W.-R. Huang, and C.-Y. Tsai \\ Research Center for Environmental Changes, Academia Sinica, Taipei 11529, Taiwan \\ Correspondence to: C. C.-K. Chou (ckchou@ rcec.sinica.edu.tw) \\ Received: 7 January 2013 - Published in Atmos. Chem. Phys. Discuss.: 4 April 2013 \\ Revised: 22 July 2013 - Accepted: 29 July 2013 - Published: 6 September 2013
}

\begin{abstract}
An intensive aerosol characterization experiment was performed at the Taipei Aerosol and Radiation Observatory (TARO, $25.02^{\circ} \mathrm{N}, 121.53^{\circ} \mathrm{E}$ ) in the urban area of Taipei, Taiwan, during July 2012. Number concentration and size distribution of aerosol particles were measured continuously, which were accompanied by concurrent measurements of mass concentration of submicron particles, $\mathrm{PM}_{1}(d \leq 1 \mu \mathrm{m})$, and photolysis rate of ozone, $J\left(\mathrm{O}^{1 \mathrm{D}}\right)$. The averaged number concentrations of total ( $\left.N_{\text {total }}\right)$, accumulation mode $\left(N_{\text {acu }}\right)$, Aitken mode $\left(N_{\text {Aitken }}\right)$, and nucleation mode $\left(N_{\text {nuc }}\right)$ particles were $13.9 \times 10^{3} \mathrm{~cm}^{-3}, 1.2 \times 10^{3} \mathrm{~cm}^{-3}, 6.1 \times 10^{3} \mathrm{~cm}^{-3}$, and $6.6 \times 10^{3} \mathrm{~cm}^{-3}$, respectively. Accordingly, the ultrafine particles (UFPs, $d \leq 100 \mathrm{~nm}$ ) accounted for $91 \%$ of the total number concentration of particles measured in this study $(10 \leq d \leq 429 \mathrm{~nm})$, indicating the importance of UFPs to the air quality and radiation budget in Taipei and its surrounding areas. An averaged $N_{\text {nuc }} / \mathrm{NO}_{\mathrm{x}}$ ratio of $192.4 \mathrm{~cm}^{-3} \mathrm{ppbv}^{-1}$ was derived from nighttime measurements, which was suggested to be the characteristic of vehicle emissions that contributed to the "urban background" of nucleation mode particles throughout a day. On the contrary, it was found that the number concentration of nucleation mode particles was independent of $\mathrm{NO}_{\mathrm{x}}$ and could be elevated up to 10 times of the "urban background" levels during daytime, suggesting a substantial amount of nucleation mode particles produced from photochemical processes. Averages $( \pm 1 \sigma)$ of the diameter growth rate (GR) and formation rate of nucleation mode particles, $J_{10}$, were $11.9 \pm 10.6 \mathrm{~nm} \mathrm{~h}^{-1}$ and $6.9 \pm 3.0 \mathrm{~cm}^{-3} \mathrm{~s}^{-1}$, respectively. Consistency in the time series of the nucleation mode particle concentration and the proxy of $\mathrm{H}_{2} \mathrm{SO}_{4}$ production, $\mathrm{UVB} \cdot \mathrm{SO}_{2} / \mathrm{CS}$, for new particle formation (NPF) events suggested that photooxidation of $\mathrm{SO}_{2}$ was likely one of the major mechanisms for the formation of new particles in our
\end{abstract}

study area. Moreover, it was revealed that the particle growth rate correlated exponentially with the photolysis of ozone, implying that the condensable vapors were produced mostly from photooxidation reactions. In addition, this study also revealed that $N_{\text {nuc }}$ exhibited a quadratic relationship with $J_{10}$. The quadratic relationship was inferred as a result of aerosol dynamics and featured NPF processes in urban areas.

\section{Introduction}

Atmospheric particulate matter (PM) is one of the main pollutants that play an important role in air quality and climate. PM interacts with solar radiation and alters the climate forcing directly (Charlson et al., 1992; Myhre, 2009), and acts as cloud condensation nuclei (CCN) to influence the cloud formation processes (Twomey, 1977; Wang and Penner, 2009). PM is also found to induce respiratory and cardiovascular diseases when they are breathed in (Nel, 2005).

While the air quality standards have been set up for the mass concentrations of $\mathrm{PM}_{10}$ and $\mathrm{PM}_{2.5}$ (particulate matter with aerodynamic diameters less than 10 or $2.5 \mu \mathrm{m}$, respectively), several studies have indicated the health effects of ultrafine particles (UFPs, $d \leq 100 \mathrm{~nm}$ ) and raised great public concerns. In contrast to the small mass fraction in PM, UFPs typically account for about two-thirds or higher of the total number concentrations of urban particulate matter (Stanier et al., 2004; Woo et al., 2001). They can penetrate deeper into human lungs than fine and coarse particles (Churg and Brauer, 2000). Oberdörster and Utell (2002) suggested that UFPs may cross the blood-brain and alveolar-capillary barriers, and enter the central nervous system. Studies have been conducted on the UFPs' impacts on morbidity and mortality 
(Wichmann et al., 2000), local and regional air quality (Cheung et al., 2012), and their spatiotemporal characteristics and formation processes in urban areas (Cheung et al., 2011; Hussein et al., 2004). Local vehicle exhaust was found to be a major source of UFPs in urban areas (Morawska et al., 2008). Particle number concentration (PNC) was positively related to the traffic volume, where the UFP number concentrations reached the daily maxima during traffic peak hours (Cheung et al., 2012), and it was affected by the measurement distance to the sources (Morawska et al., 2008). In addition to vehicle emissions, UFPs can also be formed by new particle formation (NPF) processes, which were frequently observed within urban boundary layer (e.g., Woo et al., 2001; Stanier et al., 2004; Fernández-Camacho et al., 2010; Cheung et al., 2011). Elevated particle number concentrations were found during the new particle formation events associated with photochemical production processes (Cheung et al., 2011, 2012). These studies concluded that the UFPs were contributed from the secondary formation mechanisms as well as from the primary local emissions in an urban environment.

Particle number concentration measurements conducted in urban areas of Taiwan were limited (Chang and Lee, 2007; Chen et al., 2010; Young et al., 2013). Although the relationship between PNC and local vehicle emission was studied, investigation on the influences of secondary formation on the PNC variations was relatively scarce. To understand better the characteristics of PM in terms of number concentration and the factors influencing the NPF in an urban environment, we initiated a one-month measurement campaign in an urban area of Taipei City, Taiwan, during summer 2012. The outcomes of this study are valuable to improve our understanding of the critical factors governing the NPF under an urban setting and formulation of air quality management plan.

\section{Methodology}

\subsection{The topography and meteorology of Taipei region}

Taipei metropolis is located in northern Taiwan with around 6 million inhabitants. As shown in Fig. 1, Taipei is in a topographical basin surrounded by hills of around $500-1000 \mathrm{~m}$ in elevation. Wind circulation system of Taipei is governed by the seasonal monsoons where northeasterly flow dominates in winter and southwesterly in summer, and occasionally accompanied by tropical storms or typhoons. It is dry and stable with poor dispersion conditions under a high-pressure system, but wet and unstable with good dispersion on most days. Air quality of Taipei is mainly influenced by the local emissions, in particular vehicle exhausts. In addition to the local sources, long-range transport of air pollutants from eastern China also affects air quality of northern Taiwan during the seasons of winter monsoons, while photochemical production was suggested to be a key source of fine PM in summertime (Chang and Lee, 2007, 2008).
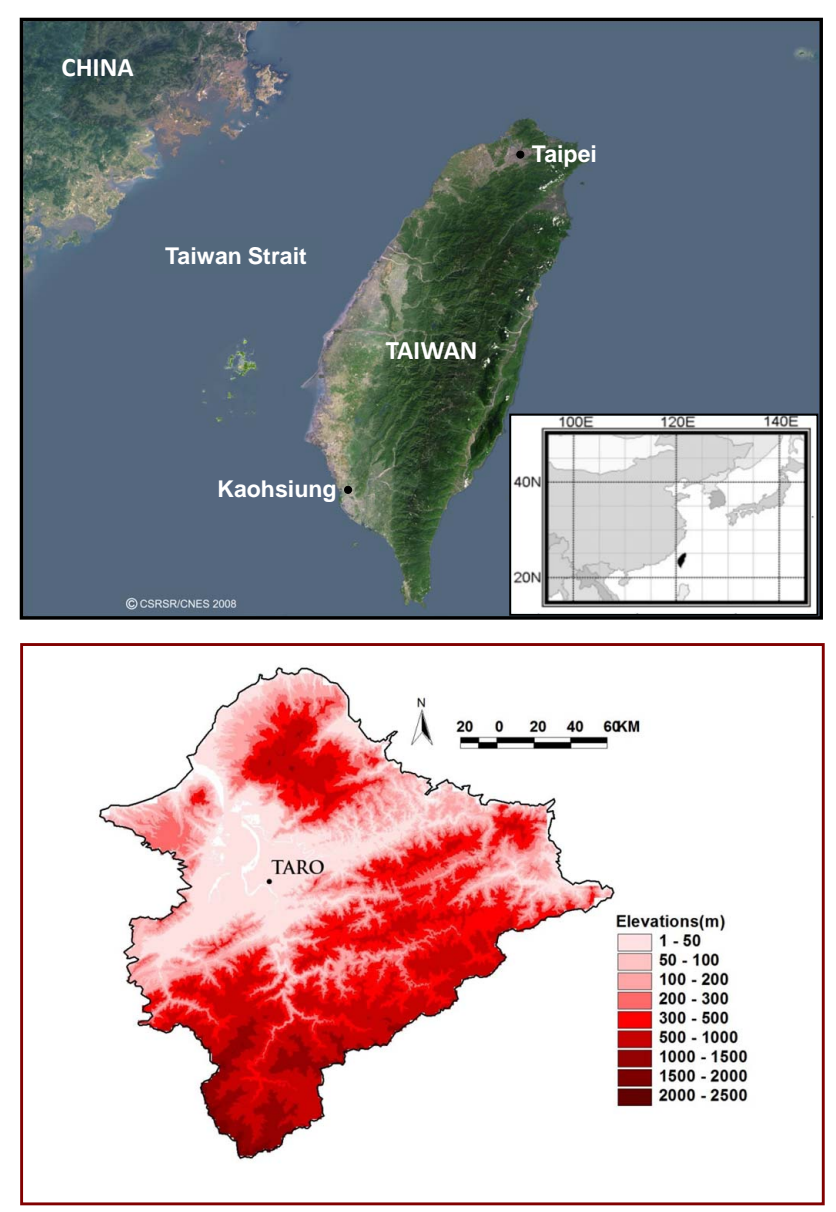

Fig. 1. Geographical locations of Taiwan in East Asia (upper panel) and the Taipei Aerosol and Radiation Observatory (TARO) in the Taipei basin (lower panel).

\subsection{Observation site and instrumentation}

The measurements were conducted at the Taipei Aerosol and Radiation Observatory (TARO, $25.02^{\circ} \mathrm{N}, 121.53^{\circ} \mathrm{E}$ ), which is located in the downtown area of Taipei City (Fig. 1), during 4-29 July 2012. The aerosol observatory is on the top floor of Building-B of the Department of Atmospheric Sciences, National Taiwan University (ASNTU), which is $\sim 20 \mathrm{~m}$ a.g.l.

Particle size distribution in the range of $10-429 \mathrm{~nm}$ was measured by a scanning mobility particle sizer (SMPS) system, which consisted of two parts: an electrostatic classifier (EC) (model: TSI 3080, TSI Inc.) and a condensation particle counter (CPC) (model: TSI 3786, TSI Inc.). The EC was equipped with a long-differential mobility analyzer (longDMA, model: TSI 3081, TSI Inc.), which can separate the poly-disperse particles into selected mono-disperse particles according to their electrostatic mobility. The number concentration of the mono-disperse particles was then counted by the CPC. Each ambient sample was drawn into the SMPS system from outside the building through a $0.635 \mathrm{~cm}$ 
(inner diameter) conductive tube, and a sampling duration of 5 min was adopted for each particle size distribution measurement. The SMPS system was operated with the sheath and aerosol flow rates of $6 \mathrm{Lpm}$ and $0.6 \mathrm{Lpm}$, respectively. The system flow rates were checked weekly during the sampling period. Besides, the accuracy of the particle sizing of EC was checked using polystyrene latex spheres (PSLs) before the campaign. The nominal diameters of the PSLs were $97 \pm 3.7 \mathrm{~nm}$ (Part\#: 3100A, lot\#: 35431, Thermo Scientific Inc.) and $350 \pm 6.0 \mathrm{~nm}$ (Part\#: 3500A, lot\#: 35910, Thermo Scientific Inc.). The measured sizes of the PSLs by the SMPS were found to be $97.5 \pm 0.3 \mathrm{~nm}$ and $341.9 \pm 5.2 \mathrm{~nm}$, respectively. Less than $3 \%$ differences between the nominal and measured diameters were obtained. Multiple charge and diffusion loss corrections (inside SMPS instrument) were applied to the particle size distribution measurements using the internal algorithm from the Aerosol Instrument Manager Software. Furthermore, diffusion loss in sampling tube was corrected according to the algorithm proposed by Holman (1972).

During the study period, continuous measurement of $\mathrm{PM}_{1}$ (particulate matter with aerodynamic diameters less than $1 \mu \mathrm{m})$ mass concentration with time resolution of one hour was also conducted at TARO using a tapered element oscillating microbalance (TEOM) (model: TEOM 1405, Thermo Scientific Inc.) equipped with the Filter Dynamics Measurement System (FDMS) and a $1 \mu \mathrm{m}$ Sharp Cut Cyclone (model: SCC-2.229, BGI Inc.) at the inlet. Besides, the photolysis rate of ozone, $J\left(\mathrm{O}^{1 \mathrm{D}}\right)$, was measured using an actinic and irradiance spectral radiometer (Metcon $\mathrm{GmbH}$, Germany). Moreover, to support the data interpretation of pollution sources, the hourly averaged mass concentrations of $\mathrm{PM}_{10}$ and $\mathrm{PM}_{2.5}$ and the mixing ratios of $\mathrm{O}_{3}, \mathrm{NO}_{\mathrm{x}}$ and $\mathrm{SO}_{2}$ as well as the meteorological parameters (including ambient temperature, humidity, and wind speed/direction) from the Guting air quality station of Taiwan Environmental Protection Agency (Taiwan EPA), which is about $1 \mathrm{~km}$ from the TARO, were analyzed in this study. The mixing ratio of $\mathrm{O}_{3}$ was measured using an UV photometry instrument (Ecotech 9810, with detection limit of $0.5 \mathrm{ppbv}$ and accuracy of $\pm 1 \%$ ); oxide of nitrogen $\left(\mathrm{NO}_{\mathrm{x}}\right)$ was measured using a chemiluminescence analyzer (Ecotech 9841, with detection limit of $0.5 \mathrm{ppbv}$ and accuracy of $\pm 1 \%$ of instrument reading); $\mathrm{SO}_{2}$ was measured by a pulsed UV fluorescence analyzer (Ecotech 9850, with detection limit of $0.5 \mathrm{ppbv}$ and accuracy of $\pm 1 \%$ of instrument reading). Span and zero calibrations for all the gas analyzers were conducted on daily basis at the air quality stations of Taiwan EPA. For more details about the measurement techniques and quality control guidelines, refer to the website of Taiwan EPA (http://taqm.epa.gov.tw/taqm/en/default.aspcx).

\subsection{Data processing and analysis}

Particle number concentrations for different size ranges were calculated by the particle size distribution from SMPS mea-


Fig. 2. Daily $72 \mathrm{~h}$ backward trajectories calculated for TARO (red dot) during the period of (a) 4-19 July and (b) 20-27 July 2012. Trajectories were calculated from $100 \mathrm{~m}$ above ground level for 08:00 LT each day.

surement. The particle number concentrations were classified into $10 \leq d \leq 429 \mathrm{~nm}\left(N_{\text {total }}\right), 100 \leq d \leq 429 \mathrm{~nm}\left(N_{\mathrm{acu}}\right)$, $25 \leq d<100 \mathrm{~nm}\left(N_{\text {Aitken }}\right)$ and $d<25 \mathrm{~nm}\left(N_{\text {nuc }}\right)$, for total, accumulation mode, Aitken mode and nucleation mode, respectively. For graph plotting, time resolution of $5 \mathrm{~min}$ was used for particle data, whereas the data for trace gases and meteorological parameters were hourly based. Thus the 5 min particle number concentration and size distribution data were then calculated into hourly averages for data comparison and analysis purposes.

\section{Results and discussion}

\subsection{General description of weather conditions during measurement periods}

Backward trajectories of air masses were calculated using the HYSPLIT model of NOAA (National Oceanic and Atmospheric Administration) (Draxler, 1999) for TARO during 
Table 1. Statistic of particle mass and number concentrations measured. Units: $\mathrm{PM}_{10}, \mathrm{PM}_{2.5}$ and $\mathrm{PM}_{1}$ in $\mu \mathrm{g} \mathrm{m}^{-3}$; and for $N_{\text {total }}, N_{\text {acu }}$, $N_{\text {Aitken }}$ and $N_{\text {nuc }}$ in $\mathrm{cm}^{-3}$. Note: $\mathrm{PM}_{2.5}$ measurement interrupted during the typhoon period.

\begin{tabular}{llllll}
\hline & Parameters & Average & Median & S.D. & No. of data \\
\hline Whole period: 4-29 Jul 2012 & $\mathrm{PM}_{10}$ & 39.6 & 36.0 & 15.0 & 620 \\
& $\mathrm{PM}_{2.5}$ & 21.6 & 21.0 & 9.8 & 403 \\
& $\mathrm{PM}_{1}$ & 10.3 & 9.9 & 7.0 & 539 \\
& $N_{\text {total }}$ & $13.9 \times 10^{3}$ & $8.4 \times 10^{3}$ & $13.1 \times 10^{3}$ & 603 \\
& $N_{\text {acu }}$ & $1.2 \times 10^{3}$ & $1.1 \times 10^{3}$ & $1.1 \times 10^{3}$ & 603 \\
& $N_{\text {Aitken }}$ & $6.1 \times 10^{3}$ & $3.2 \times 10^{3}$ & $6.5 \times 10^{3}$ & 603 \\
& $N_{\text {nuc }}$ & $6.6 \times 10^{3}$ & $4.1 \times 10^{3}$ & $7.5 \times 10^{3}$ & 603 \\
\hline 4-19 Jul, and 28-29 Jul 2012 & $\mathrm{PM}_{10}$ & 44.1 & 42.0 & 14.3 & 429 \\
& $\mathrm{PM}_{2.5}$ & 21.8 & 21.0 & 9.8 & 393 \\
& $\mathrm{PM}_{1}$ & 12.6 & 11.9 & 6.5 & 403 \\
& $N_{\text {total }}$ & $17.1 \times 10^{3}$ & $12.8 \times 10^{3}$ & $13.9 \times 10^{3}$ & 412 \\
& $N_{\text {acu }}$ & $1.6 \times 10^{3}$ & $1.5 \times 10^{3}$ & $1.0 \times 10^{3}$ & 412 \\
& $N_{\text {Aitken }}$ & $7.7 \times 10^{3}$ & $5.5 \times 10^{3}$ & $7.0 \times 10^{3}$ & 412 \\
& $N_{\text {nuc }}$ & $7.7 \times 10^{3}$ & $5.0 \times 10^{3}$ & $8.3 \times 10^{3}$ & 412 \\
\hline Cyclonic period: 20-27 Jul 2012 & $\mathrm{PM}_{10}$ & 29.5 & 28.0 & 11.1 & 191 \\
& $\mathrm{PM}_{2.5}$ & 14.7 & 14.5 & 6.6 & 10 \\
& $\mathrm{PM}$ & 3.5 & 2.8 & 3.0 & 136 \\
& $N_{\text {total }}$ & $7.0 \times 10^{3}$ & $4.9 \times 10^{3}$ & $7.4 \times 10^{3}$ & 191 \\
& $N_{\text {acu }}$ & $0.4 \times 10^{3}$ & $0.3 \times 10^{3}$ & $0.3 \times 10^{3}$ & 191 \\
& $N_{\text {Aitken }}$ & $2.5 \times 10^{3}$ & $1.6 \times 10^{3}$ & $3.3 \times 10^{3}$ & 191 \\
& $N_{\text {nuc }}$ & $4.1 \times 10^{3}$ & $3.1 \times 10^{3}$ & $4.1 \times 10^{3}$ & 191 \\
\hline & & & & &
\end{tabular}

the sampling period. During the early period of the campaign (4-19 July), southwesterly winds were found to prevail under the influences of summer monsoons (see Fig. 2a). For the later period (20-27 July), easterly winds were dominating due to the influences of the cyclonic system that developed near southern Taiwan (see Fig. 2b). Showers were occasionally observed in the afternoon during the sampling period.

\subsection{Overall statistics of particle measurement}

Statistics of particle number and mass concentrations are shown in Table 1 . The overall $N_{\text {total }}, N_{\text {acu }}, N_{\text {Aitken }}$ and $N_{\text {nuc }}$ were found to be $13.9 \times 10^{3} \mathrm{~cm}^{-3}, 1.2 \times 10^{3} \mathrm{~cm}^{-3}$, $6.1 \times 10^{3} \mathrm{~cm}^{-3}$, and $6.6 \times 10^{3} \mathrm{~cm}^{-3}$, respectively. The $N_{\text {total }}$ was comparable to urban areas including Brisbane, Australia (Cheung et al., 2011); Helsinki, Finland (Hussein et al., 2004); Yangtze River delta, China (Gao et al., 2009); Barcelona, Spain (Pey et al., 2008); and Atlanta, United States (Woo et al., 2001). However, the $N_{\text {total }}$ measured at TARO in the current study was significantly lower than that observed in urban central Taiwan, which was $3.8 \times 10^{4} \mathrm{~cm}^{-3}$ during the summertime (Young et al., 2012). Note that, in the latter study, NPF events occurred almost every day during the study period due to the presence of numerous industrial emission sources within the study region, which were suggested to induce a significantly higher PNC.
The particle mass concentrations of $\mathrm{PM}_{10}, \mathrm{PM}_{2.5}$ and $\mathrm{PM}_{1}$ were $39.6 \mu \mathrm{g} \mathrm{m}^{-3}, 21.6 \mu \mathrm{g} \mathrm{m}^{-3}$, and $10.3 \mu \mathrm{g} \mathrm{m}^{-3}$, respectively, for the entire sampling period. The number and mass concentrations of particles were found to be significantly lower under the influences of the cyclonic system. For example, the averaged $\mathrm{PM}_{1}$ and $N_{\text {total }}$ were $3.5 \mu \mathrm{g} \mathrm{m}^{-3}$ and $7.0 \times 10^{3} \mathrm{~cm}^{-3}$ under the cyclonic system, while $12.6 \mu \mathrm{g} \mathrm{m}^{-3}$ and $17.1 \times 10^{3} \mathrm{~cm}^{-3}$ were obtained for other days. The lower particle concentrations could be attributed to the stronger atmospheric dispersion associated with the cyclonic system. Relatively higher wind speed was measured during this period, which was $3.4 \mathrm{~m} \mathrm{~s}^{-1}$, compared to $1.9 \mathrm{~m} \mathrm{~s}^{-1}$ for other days. In addition to the dispersion, strong surface winds can affect two particle dynamic processes: condensation of semi-volatile gases and coagulation among the freshly formed particles and/or the preexisting aerosol particles.

\subsection{Relationship between PNC and other parameters}

Relationship between PNC and other parameters were further assessed in this section. Pearson's correlation coefficients, $r$, were calculated between PNC and particle mass concentrations and primary gaseous pollutants (i.e., $\mathrm{NO}_{\mathrm{x}}$ and $\mathrm{SO}_{2}$ ). The scatterplots between $\mathrm{PNC}$ and $\mathrm{PM}_{2.5}$ are depicted in Fig. 3a-c. In general, PNC does not show a strong correlation with mass concentrations. For example, the $r$ value 

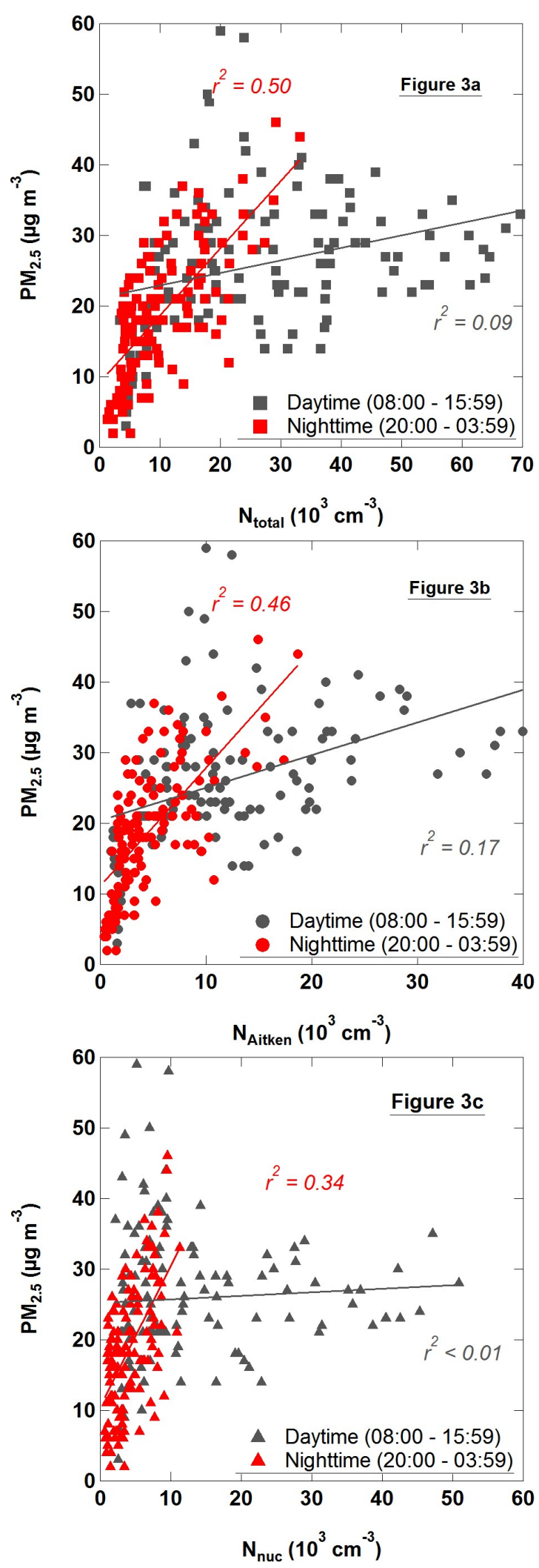

Fig. 3. Scatterplots of number concentrations (a) $N_{\text {total }}$, (b) $N_{\text {Aitken }}$ and (c) $N_{\text {nuc }}$ against $\mathrm{PM}_{2.5}$. Nighttime data are highlighted with red symbols, and daytime data are shown in grey symbols.
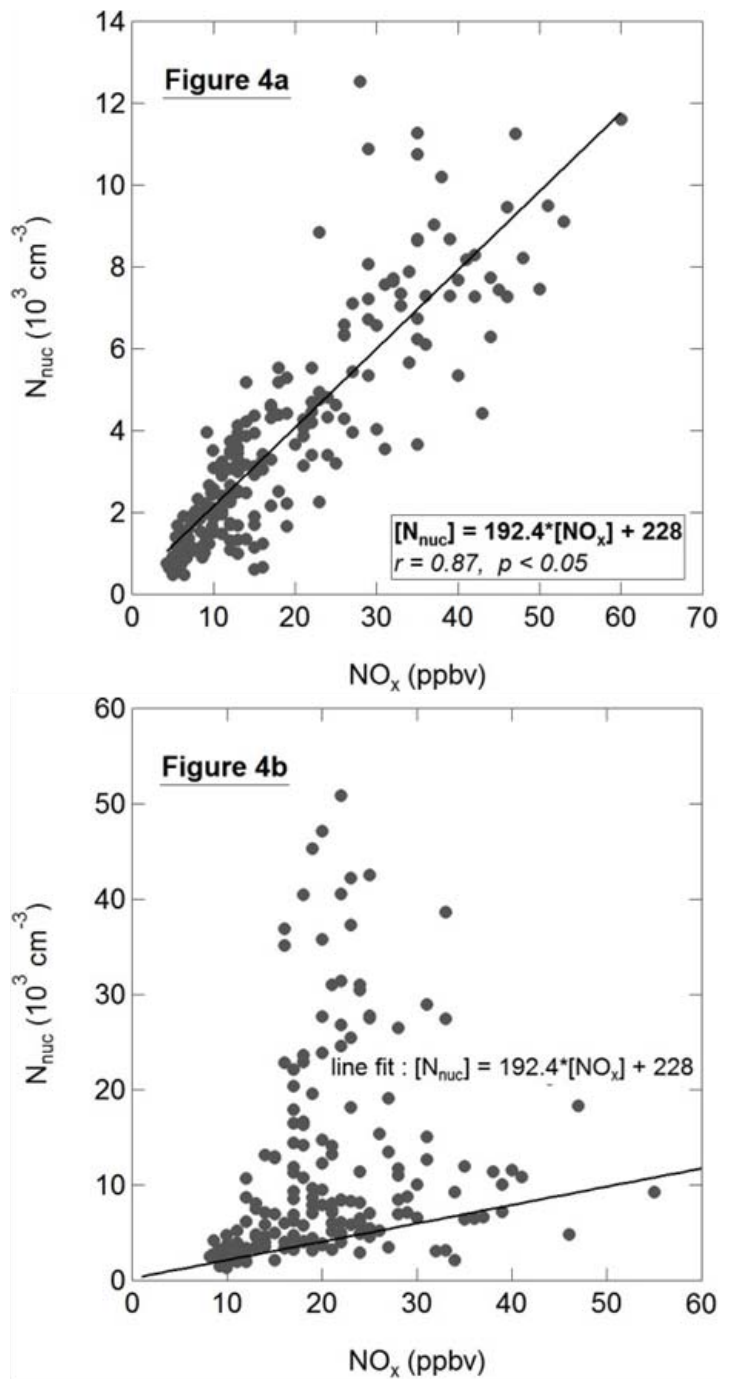

Fig. 4. Scatterplots of number concentrations of nucleation mode particle $\left(N_{\text {nuc }}\right)$ against mixing ratio of $\mathrm{NO}_{x}$ during (a) nighttime (20:00-03:59 LT) and (b) daytime (08:00-15:59 LT). The regression line obtained for nighttime data (a) was superposed onto the daytime data (b) to indicate the relationship between $N_{\text {nuc }}$ and $\mathrm{NO}_{\mathrm{x}}$ without disturbance from photochemical reactions.

between $\mathrm{PM}_{2.5}$ and $N_{\text {nuc }}$ was found to be $0.31(p<0.05)$. However, a moderate linear relationship between PNC and $\mathrm{PM}_{2.5}$ was found when only the nighttime data were considered $\left(0.34<r^{2}<0.50\right.$; highlighted in red color). In contrast, no correlation was found between $\mathrm{PNC}$ and $\mathrm{PM}_{2.5}$ for daytime data. The result suggested that the daytime and nighttime PNC were affected by different factors.

To examine the relationship between $N_{\text {nuc }}$ and vehicle exhaust emissions better, $N_{\text {nuc }}$ and $\mathrm{NO}_{\text {x }}$ were plotted in scatterplots for the daytime and nighttime, respectively, where the mixing ratio of $\mathrm{NO}_{\mathrm{x}}$ was used as an indicator of local vehicle emissions. For the nighttime data (see Fig. 4a), a significant linear correlation between $N_{\text {nuc }}$ and $\mathrm{NO}_{\mathrm{x}}$ was obtained 


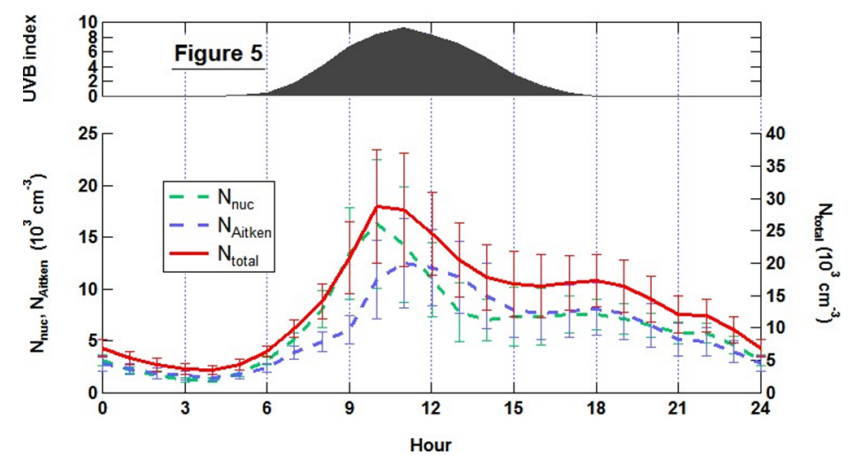

Fig. 5. Diurnal variation of particle number concentrations of total ( $N_{\text {total }}$, red solid line $)$, Aitken $\left(N_{\text {Aitken }}\right.$, blue dash line $)$, and nucleation ( $N_{\text {nuc }}$, green dash line) modes in lower panel, also UVB index in upper panel. The error bars show the values of $95 \%$ confidence interval.

( $r=0.87, p<0.05)$, suggesting that vehicle exhaust emission was the predominant source of nucleation mode particles. The slope of $192.4 \mathrm{~cm}^{-3} N_{\text {nuc }}$ per ppbv of $\mathrm{NO}_{\mathrm{x}}$ characterizes the emissions from vehicles, which contributed to the background level of nucleation mode particles in an urban area. Note that this emission ratio was applicable only for the study area, since it would depend on the local emission properties (i.e., types of fuel and vehicles) and meteorological conditions. Figure $4 \mathrm{~b}$ shows the daytime data of $N_{\text {nuc }}$ against $\mathrm{NO}_{\mathrm{x}}$ with a line fit obtained from Fig. 4a to represent the "urban background" $N_{\text {nuc }}$ contributed by vehicles. Note that, at times, the daytime $N_{\text {nuc }}$ was enhanced up to 10 times the level estimated by the $N_{\text {nuc }} / \mathrm{NO}_{\mathrm{x}}$ emission ratio. The results suggest that, in the budget of $N_{\text {nuc }}$ of urban Taipei, the primary $\left(\mathrm{NO}_{\mathrm{x}}\right.$ relevant) sources contributed throughout a day, whereas the other $\left(\mathrm{NO}_{\mathrm{x}}\right.$ independent) sources dominated during daytime, in particular the episodes of new particle burst. Previous studies of NPF events in urban areas showed that the burst of nucleation mode particles was associated strongly with photochemical production of sulfuric acid (Woo et al., 2001; Stanier et al., 2004; Cheung et al., 2012). A similar finding has been reported in another polluted urban area of central Taiwan (Young et al., 2012). The discussion on the NPF will be provided in the following sections.

\subsection{Observation of new particle formation}

A NPF event is defined as the increase of the number concentration of nucleation mode particles, and those particles are growing into Aitken and/or accumulation mode size range $(\geq 25 \mathrm{~nm}$ ) and last for a few hours until they disappear into the atmosphere by condensation/coagulation sinks (Dal Maso et al., 2005). Averaged diurnal variations of $N_{\text {total }}$ and UVB (ultraviolet B, wavelength ranging from 315 to $280 \mathrm{~nm}$ ) for this study are depicted in Fig. 5. Two peaks were observed for $N_{\text {total }}$ at 11:00 LT and 18:00 LT. The first one was most likely contributed by NPF, which was associated with daily maxima of UVB, whereas the second peak showed the influence of traffic emission in late afternoon. We then separate the $N_{\text {total }}$ into three size bins as described in Sect. 2.3, and the diurnal variations in the number concentrations for nucleation and Aitken mode particles ( $N_{\text {nuc }}$ and $\left.N_{\text {Aitken }}\right)$ are also illustrated in Fig. 5, respectively. A mode of $N_{\text {nuc }}$ was observed near 10:00 LT, and the peak of $N_{\text {Aitken }}$ was observed one hour later. This suggested that nucleation mode particles were formed in the morning where particles have subsequently grown into larger sizes (Cheung et al., 2011).

During the study period, a total of nine NPF events were observed. NPF events occurred frequently in the period from 8 to 19 July ( 8 events in 12 days) and on 27 July. Figure 6 shows the time series of particle size distribution (lower panel), $N_{\text {total }}$ (middle panel) and wind direction/speed (upper panel) for the entire campaign period. The general meteorological conditions for the NPF events were sunny day with southwesterly to northwesterly winds during initial stage of the events. The averaged daytime (08:00-16:00LT) wind speeds for NPF event and non-event days were $2.61 \mathrm{~m} \mathrm{~s}^{-1}\left( \pm 0.43 \mathrm{~m} \mathrm{~s}^{-1}\right)$ and $3.23 \mathrm{~m} \mathrm{~s}^{-1}\left( \pm 1.45 \mathrm{~m} \mathrm{~s}^{-1}\right)$, respectively. The relatively lower and lesser fluctuation wind speed on NPF days implied a stable atmospheric condition setting favorable for the new particle formation. Higher mean $N_{\text {total }}$ and $N_{\text {nuc }}$ were found to be $20.3 \times 10^{3} \mathrm{~cm}^{-3}$ and $9.4 \times 10^{3} \mathrm{~cm}^{-3}$ for NPF event days compared to that for non-event days $\left(N_{\text {total }}=10.4 \times 10^{3} \mathrm{~cm}^{-3}\right.$ and $N_{\text {nuc }}=5.0 \times 10^{3} \mathrm{~cm}^{-3} ;$ see Table 2). Also the 95 th percentile of $N_{\text {nuc }}\left(31.0 \times 10^{3} \mathrm{~cm}^{-3}\right)$ during the NPF event was twice of that measured on nonevent days. These results suggested that the burst of nucleation mode particles induced by the NPF had caused a significant impact on the particle number concentration during this campaign period.

During the NPF events, the variation of $N_{\text {nuc }}$ was found to be coincident with an index of photochemical production of ambient $\mathrm{H}_{2} \mathrm{SO}_{4}$, which was defined by the product of UVB and $\mathrm{SO}_{2}$ divided by the particle condensation sink (UVB $\cdot \mathrm{SO}_{2} / \mathrm{CS}$ ). Figure 7 shows the time series of $N_{\text {nuc }}$ and $\mathrm{UVB} \cdot \mathrm{SO}_{2} / \mathrm{CS}$ (upper panel) and the particle size distributions from 8-14 July during which consecutive nucleation events were observed. The $N_{\text {nuc }}$ and UVB $\cdot \mathrm{SO}_{2} / \mathrm{CS}$ were fairly correlated in log-normal relationship with $r^{2}$ of 0.5 (see Figure S1 in the Supplement for the scatterplot between $N_{\text {nuc }}$ and $\left.\mathrm{UVB} \cdot \mathrm{SO}_{2} / \mathrm{CS}\right)$. This implies that the increases of the $N_{\text {nuc }}$ during the NPF events were also contributed by other sources, for example the local vehicle emission, which was mentioned in Sect. 3.3. Nevertheless, the results suggested that $\mathrm{H}_{2} \mathrm{SO}_{4}$ may have contributed substantially to the particle formation process in our study region.

We further investigated the sources of $\mathrm{SO}_{2}$ influencing the NPF around Taipei City. Figure 8 shows averaged $\mathrm{SO}_{2}$ mixing ratios over Taipei region during the study period (only daytime 08:00-15:59 LT was used). The results showed that 


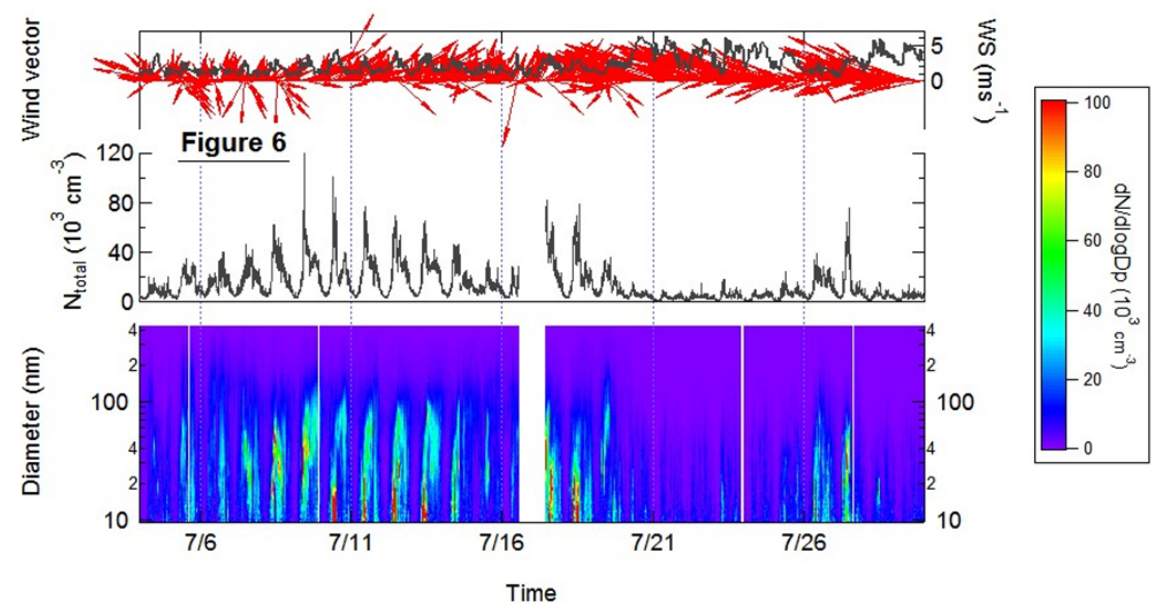

Fig. 6. Time series of measured parameters for summer 2012. From bottom to upper panels are (i) particle size distribution, (ii) total particle number concentration $\left(N_{\text {total }}\right)$ and (iii) wind direction (wind vector) and speed (WS).

Table 2. Statistic of particle number concentrations measured during NPF event days and non-event days. Unit: $\mathrm{cm}^{-3}$ for $N_{\text {total }}, N_{\text {acu }}$, $N_{\text {Aitken }}$ and $N_{\text {nuc. }}$.

\begin{tabular}{lllllll}
\hline & Parameters & Average & Median & 95th percentile & S.D. & No. of data \\
\hline \multirow{2}{*}{ NPF event days } & $N_{\text {total }}$ & $20.3 \times 10^{3}$ & $16.4 \times 10^{3}$ & $50.5 \times 10^{3}$ & $14.9 \times 10^{3}$ & 216 \\
& $N_{\text {acu }}$ & $1.6 \times 10^{3}$ & $1.4 \times 10^{3}$ & $3.5 \times 10^{3}$ & $0.9 \times 10^{3}$ & 216 \\
& $N_{\text {Aitken }}$ & $9.3 \times 10^{3}$ & $6.7 \times 10^{3}$ & $23.2 \times 10^{3}$ & $7.6 \times 10^{3}$ & 216 \\
& $N_{\text {nuc }}$ & $9.4 \times 10^{3}$ & $6.8 \times 10^{3}$ & $31.0 \times 10^{3}$ & $9.2 \times 10^{3}$ & 216 \\
\hline \multirow{2}{*}{ Non-event days } & $N_{\text {total }}$ & $10.4 \times 10^{3}$ & $6.4 \times 10^{3}$ & $28.7 \times 10^{3}$ & $10.4 \times 10^{3}$ & 387 \\
& $N_{\text {acu }}$ & $1.0 \times 10^{3}$ & $0.4 \times 10^{3}$ & $3.3 \times 10^{3}$ & $1.1 \times 10^{3}$ & 387 \\
& $N_{\text {Aitken }}$ & $4.3 \times 10^{3}$ & $2.2 \times 10^{3}$ & $13.4 \times 10^{3}$ & $5.0 \times 10^{3}$ & 387 \\
& $N_{\text {nuc }}$ & $5.0 \times 10^{3}$ & $3.4 \times 10^{3}$ & $13.4 \times 10^{3}$ & $5.8 \times 10^{3}$ & 387 \\
\hline
\end{tabular}

two hot spots were observed with relatively higher $\mathrm{SO}_{2}$ levels located at (i) the east rim of Taipei basin and (ii) the southwest of Taipei basin. Truck emission is most likely the major source responsible for the eastern $\mathrm{SO}_{2}$ hot spot; however, the plumes from the coal fire power plant located in northeastern Taiwan were also possible source. Industrial and vehicle exhaust emissions (diesel engine vehicles) were major sources of $\mathrm{SO}_{2}$ hot spot observed in western Taipei. Land and sea breeze comprise a synoptic wind pattern affecting Taipei City, with south-westerly/westerly winds dominating in the morning, and the wind direction shifted clockwise to easterly in afternoon. In the Supplement of this paper, Fig. S2 shows the hourly contour plots of $\mathrm{SO}_{2}$ (from 07:00 to 12:00 LT) over Taipei region during the NPF event on 8 July 2012. A relatively high $\mathrm{SO}_{2}(\sim 10 \mathrm{ppb})$ was observed in western Taipei, whereas $\mathrm{SO}_{2}$ was found to be below $2 \mathrm{ppb}$ around TARO, central Taipei, at 07:00 LT. During the morning of 8 July, westerly wind was dominating, which could bring the $\mathrm{SO}_{2}$ plume to the TARO. The observation found that the NPF event initiated at 11:00 LT, when the $\mathrm{SO}_{2}$ reached the daily maxima of $5 \mathrm{ppb}$. The characteristics in winds and $\mathrm{SO}_{2}$ de- scribed above hold for most of the NPF events except the case on 27 July 2012, where easterly winds dominated with elevated $\mathrm{SO}_{2}$ east of TARO at around 09:00-10:00 LT (see Fig. S3). From these cases, we can see that the transport of $\mathrm{SO}_{2}$ from the sources around Taipei has substantial impacts upon particle formation process and, thereby, the number concentration of UFPs in urban Taipei.

\subsection{Growth and formation rates}

Table 3 summarizes the averaged growth rate (GR) and formation rate of nucleation mode particles $\left(J_{10}\right)$, and relevant measurements for respective nucleation events observed in this study. The averaged GR was found to be $11.9 \pm 10.6 \mathrm{~nm} \mathrm{~h}^{-1}$ (ranged from 4.4 to $38.7 \mathrm{~nm} \mathrm{~h}^{-1}$ ). The average and range of GR values are comparable to those observed in a previous urban study in central Taiwan, which was $11.8 \mathrm{~nm} \mathrm{~h}^{-1}$ on average and ranged from 6.7 to $23.9 \mathrm{~nm} \mathrm{~h}^{-1}$ (Young et al. 2013), as well as to observations for other urban areas like Atlanta, United States, with averaged GR of $9.3 \mathrm{~nm} \mathrm{~h}^{-1}$ (Stolzenburg et al., 2005), whereas 
Table 3. Summary of averaged particle number concentration, growth rate, formation rate and ozone photolysis measurements for NPF events. Note: start and end time refer to the period of nucleation mode particles growing through $25 \mathrm{~nm}$, which are used to calculate the growth rate (GR).

\begin{tabular}{llllllllll}
\hline Event date & Start time & End time & $\begin{array}{l}\mathrm{GR} \\
\left(\mathrm{nm} \mathrm{h}^{-1}\right)\end{array}$ & $\begin{array}{l}J_{10} \\
\left(\mathrm{~cm}^{-3} \mathrm{~s}^{-1}\right)\end{array}$ & $\begin{array}{l}\mathrm{N}_{\text {total }} \\
\left(\mathrm{cm}^{-3}\right)\end{array}$ & $\begin{array}{l}\mathrm{N}_{\text {nuc }} \\
\left(\mathrm{cm}^{-3}\right)\end{array}$ & $\begin{array}{l}\mathrm{O}_{3} \\
(\mathrm{ppb})\end{array}$ & $\begin{array}{l}J\left(\mathrm{O}^{1 \mathrm{D}}\right) \\
\left(10^{-5} \mathrm{~s}^{-1}\right)\end{array}$ & $\begin{array}{l}J\left(\mathrm{O}^{1 \mathrm{D}}\right) \cdot \mathrm{O}_{3} \\
\left(\mathrm{ppt} \mathrm{s}^{-1}\right)\end{array}$ \\
\hline $2012 / 7 / 08$ & $09: 00$ & $11: 00$ & 4.4 & 7.7 & $43.8 \times 10^{3}$ & $29.5 \times 10^{3}$ & 36 & 3.50 & 1.26 \\
$2012 / 7 / 09$ & $09: 40$ & $10: 20$ & 38.7 & 12.5 & $56.6 \times 10^{3}$ & $31.0 \times 10^{3}$ & 47 & 3.41 & 1.60 \\
$2012 / 7 / 11$ & $10: 00$ & $11: 45$ & 6.3 & 9.3 & $60.1 \times 10^{3}$ & $45.0 \times 10^{3}$ & 48 & 3.59 & 1.72 \\
$2012 / 7 / 12$ & $09: 15$ & $11: 05$ & 6.5 & 7.0 & $49.2 \times 10^{3}$ & $37.9 \times 10^{3}$ & 33.5 & 3.50 & 1.17 \\
$2012 / 7 / 13$ & $09: 00$ & $10: 55$ & 11.5 & 6.2 & $45.5 \times 10^{3}$ & $36.6 \times 10^{3}$ & 32 & 3.31 & 1.06 \\
$2012 / 7 / 14$ & $09: 00$ & $10: 05$ & 10.9 & 6.2 & $37.1 \times 10^{3}$ & $26.3 \times 10^{3}$ & 30 & 3.24 & 0.97 \\
$2012 / 7 / 18$ & $09: 00$ & $10: 55$ & 6.6 & 6.7 & $51.3 \times 10^{3}$ & $37.8 \times 10^{3}$ & 27 & 1.64 & 0.44 \\
$2012 / 7 / 19$ & $09: 00$ & $09: 45$ & 15.6 & 1.4 & $21.7 \times 10^{3}$ & $10.3 \times 10^{3}$ & 49 & 3.12 & 1.53 \\
$2012 / 7 / 27$ & $09: 00$ & $10: 25$ & 6.6 & 5.2 & $41.1 \times 10^{3}$ & $27.6 \times 10^{3}$ & 26 & 3.45 & 0.90 \\
\hline
\end{tabular}

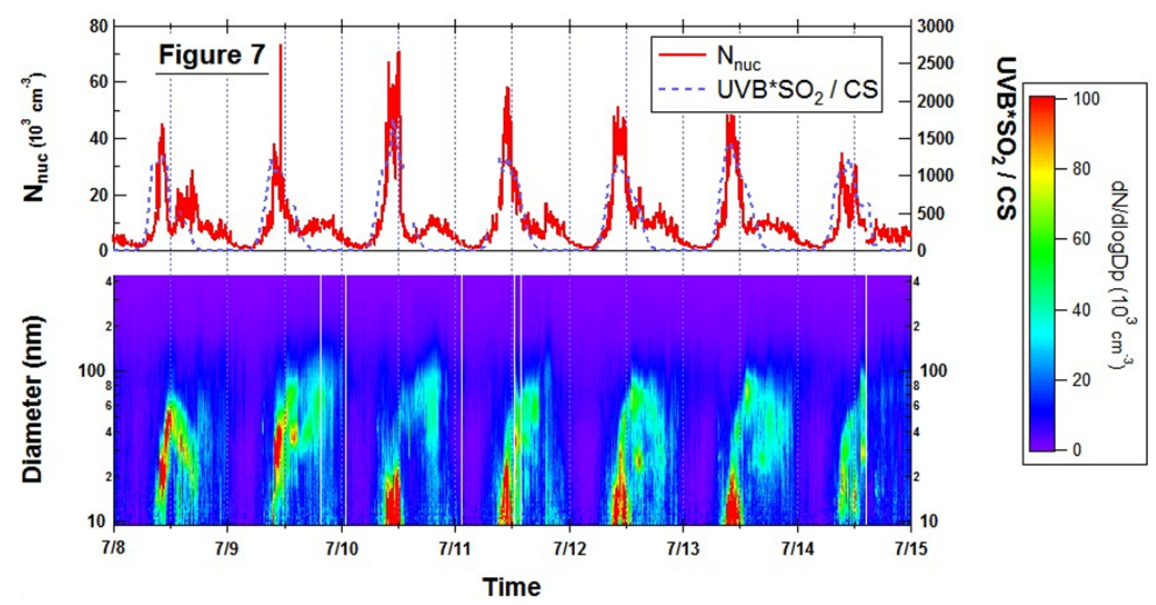

Fig. 7. Time series of particle size distribution (lower panel) and number concentration of nucleation mode $\left(N_{\text {nuc }}\right)$ and $\mathrm{UVB} \cdot \mathrm{SO} / \mathrm{CS}(\mathrm{upper}$ panel) for 8-14 July 2012.

significantly lower GR of $6.0 \mathrm{~nm} \mathrm{~h}^{-1}$ was reported for Beijing, China (Zhang et al., 2011). Previous studies suggested that the variations in GR values were associated with the meteorological conditions (e.g., temperature, $\mathrm{RH}$ ) and the production of condensable vapors (Cheung et al., 2011; Yli-Juuti et al., 2011). Figure 9 illustrates the correlation between GR and the product of $J\left(\mathrm{O}^{1 \mathrm{D}}\right)$ and mixing ratio of ozone, which gives the production rate of $\mathrm{OH}$ radicals from ozone photolysis. It was revealed that the value of GR increased with photolysis of ozone and in turn the production of $\mathrm{OH}$ radicals. The relationship between GR and ozone photolysis is depicted exponentially and suggests that the GR could be changing nonlinearly with $\mathrm{OH}$ production. One plausible explanation of the nonlinear relationship is that production of $\mathrm{OH}$ radicals can contribute to GR not only for the production of condensable vapors that condense onto particles, but also via formation of new tiny particles that could coagulate with preexisting particles and enhance the apparent growth rate. Thus the significant correlation between GR and $\mathrm{OH}$ production warrants that the growth of newly formed particles was driven by production of condensable vapors, either organics or $\mathrm{H}_{2} \mathrm{SO}_{4}$, from photochemical reactions. However, as the data from this study characterized the relationship between GR and ozone photolysis, further studies to link the photochemical dynamics and microphysical behavior of aerosols are needed to validate the hypothesis of nonlinear growth. The outlier shown in Fig. 9 is for the event on 11 July. The causes of that discrepancy are yet unclear; nevertheless, preliminary investigation suggested that the growth of particle could have been inhibited by stronger winds during that morning (shown in Fig. S4).

Averaged formation rate of nucleation mode particles $\left(J_{10}\right)$ for each NPF event was calculated for the particle size ranging from $\sim 10$ to $25 \mathrm{~nm}$ according to the method of Dal Maso et al. (2005). Formation rate is defined as the sum of the apparent formation rate $\left(\mathrm{d} N_{\text {nuc }} / \mathrm{d} t\right)$ and the coagulation loss rate during the NPF event. It should be noted that the reported apparent particle formation rate $\left(J_{10}\right)$ is expected to 


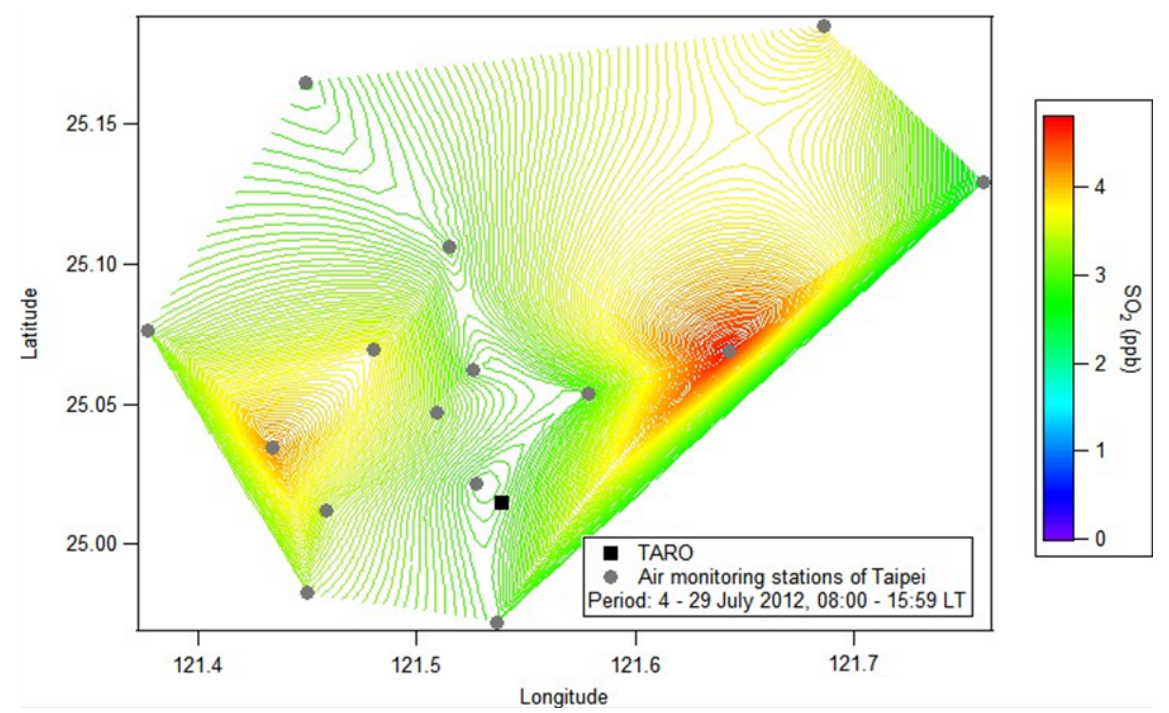

Fig. 8. Mean $\mathrm{SO}_{2}$ mixing ratio of Taipei region measured during 4-29 July 2012. Square dot: TARO. Circle dots: air-quality monitoring stations of Taiwan EPA.

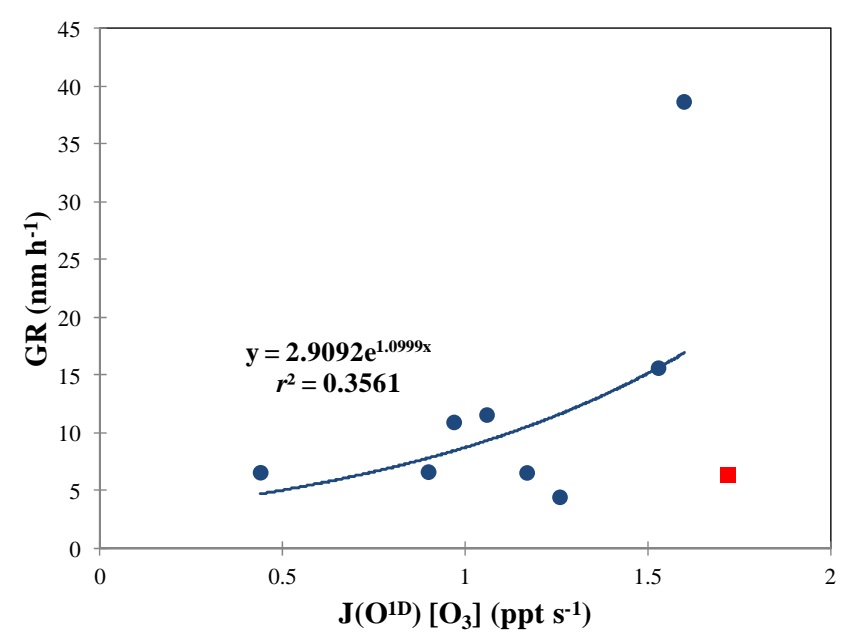

Fig. 9. Correlation between the growth rate of nucleation mode particles and the photolysis of ozone for the NPF events in this study. Photolysis of ozone is assumed to be the dominant term in the production of $\mathrm{OH}$ radicals and, thereby, used as an indicator of photochemical production of semi-volatile species that in turn condensed on the preexisting particles and contributed to the particle growth. The square denotes the outlier data point for 11 July 2012 that was excluded from the curve-fitting analysis (see main text for details).

be smaller than the actual nucleation rate (or the formation rate of $3 \mathrm{~nm}$ particle, $J_{3}$ ), since some fraction of formed nuclei is always scavenged by coagulation into larger preexisting particles before they grow larger by condensation (Lehtinen et al., 2007). The mean $J_{10}$ for the new particle events was found to be $6.9 \pm 3.0 \mathrm{~cm}^{-3} \mathrm{~s}^{-1}$. The $J_{10}$ observed in this study, ranging from 1.4 to $12.5 \mathrm{~cm}^{-3} \mathrm{~s}^{-1}$, is comparable to recent observations for NPF in urban areas such as
Budapest, Hungary $\left(J_{6}: 4.2 \mathrm{~cm}^{-3} \mathrm{~s}^{-1}\right.$ with a range of $1.65-$ $12.5 \mathrm{~cm}^{-3} \mathrm{~s}^{-1}$, Salma et al., 2011); Beijing, China $\left(J_{3}: 2-\right.$ $13 \mathrm{~cm}^{-3} \mathrm{~s}^{-1}$, Yue et al., 2010); Marseille, France $\left(J_{3}: 3-\right.$ $5.3 \mathrm{~cm}^{-3} \mathrm{~s}^{-1}$, Petäjä et al., 2007); and Athens, Greece $\left(J_{3}\right.$ : $1.3-6.5 \mathrm{~cm}^{-3} \mathrm{~s}^{-1}$, Petäjä et al., 2007). The formation rate of nano-particles is known to depend on the physical and chemical conditions of the atmosphere. In this study, the formation rate was influenced by the regional and local (both primary and secondary) sources. Also, the relatively high level of preexisting particles could have weakened the nucleation process and lowered the formation rates. Fig. 10a shows the relationship between $J_{10}$ and the total as well as the nucleation mode PNCs, $N_{\text {total }}$ and $N_{\text {nuc }}$, for the NPF events in this study. Apparently, PNCs increased with $J_{10}$ to respond to the production of new particles during a NPF event. However, $N_{\text {nuc }}$ behaved as a quadratic function and reached the maximal levels around $4.5 \times 10^{4} \mathrm{~cm}^{-3}$ with $J_{10}$ of $\sim 9 \mathrm{~cm}^{-3} \mathrm{~s}^{-1}$, whereas $N_{\text {total }}$ leveled off toward a high value of $J_{10}$. The differences between $N_{\text {total }}$ and $N_{\text {nuc }}$ indicated that the newly formed nucleation mode particles have grown rapidly beyond $25 \mathrm{~nm}$ in the case of high $J_{10}$, which is corresponding to the case with GR of $38.7 \mathrm{~nm} \mathrm{~h}^{-1}$ shown in Fig. 9 .

The dependence of GR to PNCs, $N_{\text {total }}$ and $N_{\text {nuc }}$, is illustrated in Fig. 10b. Except the case of extremely high GR, it is obvious that the values of GR decreased linearly with PNCs. The decreases in GR were inferred as a result of the increases in the availability of surface area for the condensation of vapors. The detailed mechanisms for the case of high GR $\left(37.2 \mathrm{~nm} \mathrm{~h}^{-1}\right)$ that occurred on 9 July are not yet well understood. Nevertheless, given the meteorological data as well as the ozone photolysis and PNCs observations described above, it was inferred that the extremely high GR was caused by the co-occurrence of low wind speed and high 



Fig. 10. (a) Responses of the total and nucleation mode particle number concentrations ( $N_{\text {total }}$ and $\left.N_{\text {nuc }}\right)$ to the changes in the nucleation mode particle formation rate $\left(J_{10}\right)$; (b) dependence of particle growth rate (GR) to the particle number concentrations $\left(N_{\text {total }}\right.$ and $N_{\text {nuc }}$ ) during the NPF episodes analyzed in this study. The dependencies are illustrated with quadratic (PNCs vs. $J_{10}$ ) or linear (GR vs. PNCs) curve-fitting. The open symbols in (b) denote the outlier case of extremely high GR (see main text for details).

ozone photolysis rate, which favored both production and accumulation of condensable vapors simultaneously. Moreover, the collision between particles could have been enhanced during the period of high PNCs; consequently, the GR increased further due to the combined effects of coagulation and condensation.

\section{Conclusions}

In this study, an intensive measurement campaign of particle number concentration, size distribution, and mass concentrations was conducted at an urban aerosol observa- tory (TARO) in Taipei, Taiwan, during July 2012. The results indicated that the particle number concentration of the study region was influenced primarily by the local vehicle emissions and the photochemical production in addition to the meteorological conditions. The averages of particle number concentrations $N_{\text {total }}, N_{\text {acu }}, N_{\text {Aitken }}$, and $N_{\text {nuc }}$ were $13.9 \times 10^{3} \mathrm{~cm}^{-3}, 1.2 \times 10^{3} \mathrm{~cm}^{-3}, 6.1 \times 10^{3} \mathrm{~cm}^{-3}$, and $6.6 \times 10^{3} \mathrm{~cm}^{-3}$, respectively. The UFPs (i.e., $N_{\text {Aitken }}+N_{\text {nuc }}$ ) accounted for $91 \%$ of the total number concentration of particles measured in this study $(10 \leq d \leq 429 \mathrm{~nm})$, indicating the importance of UFPs to the air quality and radiation budget in Taipei and its surrounding areas.

An averaged $N_{\text {nuc }} / \mathrm{NO}_{\mathrm{x}}$ ratio of $192.4 \mathrm{~cm}^{-3} \mathrm{ppbv}^{-1}$ was obtained from nighttime measurements, which was suggested to be the characteristic of vehicle emissions and was considered as the "urban background" of nucleation mode particles emitted from primary sources in this study area. Daytime measurements found that the number concentration of nucleation mode particles was elevated up to 10 times the "urban background" levels during NPF events, implying that the formation of new particles was driven by photochemical reactions.

In total nine NPF events were observed during the experiment period: eight of them were under typical land-sea breeze circulation, and one event was under the influence of easterly winds. Elevated particle number concentrations were observed during the NPF events with average values of $20.3 \times 10^{3} \mathrm{~cm}^{-3}\left(N_{\text {total }}\right)$, compared to $10.4 \times 10^{3} \mathrm{~cm}^{-3}$ ( $\left.N_{\text {total }}\right)$ for the non-event days. All the NPF events were found to be associated with $\mathrm{SO}_{2}$ advection. The variations in the number concentration of nucleation mode particles and the estimated $\mathrm{H}_{2} \mathrm{SO}_{4}$ proxy, $\mathrm{UVB} \cdot \mathrm{SO}_{2} / \mathrm{CS}$, were well in agreement during the NPF events, suggesting that oxidation of $\mathrm{SO}_{2}$ was likely among the major mechanisms for the NPF events. There was no NPF event observed at TARO as Taiwan was under the influence of a cyclonic system during the measurement period, which was most likely due to the enhanced atmospheric dispersion induced by the higher wind speed that suppressed the NPF occurrence.

Growth and formation rates of nucleation mode particles were retrieved from the size distribution measurements. The averages of GR and $J_{10}$ for the NPF events observed in this study were $11.9 \pm 10.6 \mathrm{~nm} \mathrm{~h}^{-1}$ and $6.9 \pm 3.0 \mathrm{~cm}^{-3} \mathrm{~s}^{-1}$, respectively. The respective ranges of GR and $J_{10}$ are comparable to the results of previous investigations on urban aerosols. Positive correlation between PNCs and $J_{10}$ was observed in most of the cases. However, it was found that $N_{\text {nuc }}$ behaved as a quadratic function and reached the maximal levels around $4.5 \times 10^{4} \mathrm{~cm}^{-3}$ with $J_{10}$ of $\sim 9 \mathrm{~cm}^{-3} \mathrm{~s}^{-1}$, whereas $N_{\text {total }}$ leveled off toward a high value of $J_{10}$. The differences between $N_{\text {total }}$ and $N_{\text {nuc }}$ suggest that the lifetimes of newly formed nucleation mode particles have reduced in the case of high GR and $J_{10}$.

Analysis on the correlation between GR and the photolysis of ozone revealed that GR increased exponentially with 
the production of $\mathrm{OH}$ radicals, suggesting that the growth of nano-particles was dominated by the production of semivolatile species from photooxidation. Unfortunately, without measurements of the composition of aerosols and precursor gases, the species responsible for the growth of aerosols remain unclear. In addition, the values of GR were also found to depend negatively on the number concentration of particles. It was inferred that the GR was regulated by the availability of surface areas for vapor condensation and thereby declined with increases in PNCs.

\section{Supplementary material related to this article is available online at: http://www.atmos-chem-phys.net/13/ 8935/2013/acp-13-8935-2013-supplement.pdf.}

Acknowledgements. The authors gratefully acknowledge the logistic support from the department of atmospheric sciences, National Taiwan University, and the financial support from the Academia Sinica and the National Science Council through grants 99-2111-M-001-005-MY3, 100-2111-M-001-003, and 101-2119M-001-003. Also we thank the Taiwan EPA for providing the air quality and meteorological data.

Edited by: V.-M. Kerminen

\section{References}

Chang, S.-C. and Lee, C.-T.: Secondary aerosol formation through photochemical reactions estimated by using air quality monitoring data in Taipei City from 1994 to 2003, Atmos. Environ., 41, 4002-4017, 2007.

Chang, S.-C. and Lee, C.-T.: Evaluation of the temporal variations of air quality in Taipei City, Taiwan, from 1994 to 2003, J. Environ. Manage., 86, 627-635, doi:10.1016/j.jenvman.2006.12.029, 2008.

Charlson, R. J., Schwartz, S. E., Hales, J. M., Cess, R. D., Coakley Jr., J. A., Hansen, J. E., and Hofmann, D. J.: Climate forcing by anthropogenic aerosols, Science, 255, 423-430, doi:10.1126/science.255.5043.423, 1992.

Chen, S.-C., Tsai, C.-J., Chou, C. C.-K., Roam, G.-D., Cheng, S.-S., and Wang, Y.-N.: Ultrafine particles at three different sampling locations in Taiwan, Atmos. Environ., 44, 533-540, doi:10.1016/j.atmosenv.2009.10.044, 2010.

Cheung, H. C., Morawska, L., and Ristovski, Z. D.: Observation of new particle formation in subtropical urban environment, Atmos. Chem. Phys., 11, 3823-3833, doi:10.5194/acp-11-38232011, 2011.

Cheung, H. C., Morawska, L., Ristovski, Z. D., and Wainwright, D.: Influence of medium range transport of particles from nucleation burst on particle number concentration within the urban airshed, Atmos. Chem. Phys., 12, 4951-4962, doi:10.5194/acp-12-49512012, 2012.

Churg, A. and Brauer, M.: Ambient atmospheric particles in the airways of human lungs, Ultrastruct. Pathol., 24, 353-361, doi:10.1080/019131200750060014, 2000.
Dal Maso, M., Kulmala, M., Riipinen, I., Wagner, R., Hussein, T., Aalto, P. P., and Lehtinen, K. E. J.: Formation and growth of fresh atmospheric aerosols: eight years of aerosol size distribution data from SMEAR II, Hyytiälä, Finland, Boreal Environ. Res., 10, 323-336, 2005.

Draxler, R. R.: HYSPLIT4 user's guide, NOAA Tech. Memo, ERLARL-230, NOAA Air Resources Laboratory, Silver Spring, MD, USA, 1999.

Fernández-Camacho, R., Rodríguez, S., de la Rosa, J., Sánchez de la Campa, A. M., Viana, M., Alastuey, A., and Querol, X.: Ultrafine particle formation in the inland sea breeze airflow in Southwest Europe, Atmos. Chem. Phys., 10, 9615-9630, doi:10.5194/acp10-9615-2010, 2010.

Gao, J., Wang, T., Zhou, X., Wu, U., and Wang, W.: Measurement of aerosol number size distributions in the Yangtze River Delta in China: Formation and growth of particles under polluted conditions, Atmos. Environ., 43, 829-836, doi:10.1016/j.atmosenv.2008.10.046, 2009.

Holman, J. P.: Heat Transfer, New York, McGraw-Hill, 1972.

Hussein, T., Puustinen, A., Aalto, P. P., Mäkelä, J. M., Hämeri, K., and Kulmala, M.: Urban aerosol number size distribution, Atmos. Chem. Phys., 4, 391-411, doi:10.5194/acp-4-391-2004, 2004.

Lehtinen, K. E. J., Dal Maso, M., Kulmala, M., and Kerminen, V.-M.: Estimating nucleation rates from apparent particle formation rates and vice versa: Revised formulation of the Kerminen-Kulmala equation, J. Aerosol Sci., 38, 988-994, doi:10.1016/j.jaerosci.2007.06.009, 2007.

Morawska, L., Ristovski, Z., Jayaratne, E. R., Keogh, D. U., and Ling, X.: Ambient nano and ultrafine particles from motor vehicle emissions: Characteristics, ambient processing and implications on human exposure, Atmos. Environ., 42, 8113-8138, doi:10.1016/j.atmosenv.2008.07.050, 2008.

Myhre, G.: Consistency between satellite-derived and modeled estimates of the direct aerosol effect, Science, 35, 187-190, doi:10.1126/science.1174461, 2009.

Nel, A.: Air pollution-related illness: Effects of particle, Science, 308, 804-806, doi:10.1126/science.1108752, 2005.

Oberdörster, G. and Utell, M. J.: Ultrafine particle in the urban air: to the respiratory tract - and beyond?, Environ. Health Perspect., 110, A440-A441, 2002.

Petäjä, T., Kerminen, V.-M., Dal Maso, M., Junninen, H., Koponen, I. K., Hussein, T., Aalto, P. P., Andronopoulos, S., Robin, D., Hämeri, K., Bartzis, J. G., and Kulmala, M.: Submicron atmospheric aerosols in the surroundings of Marseille and Athens: physical characterization and new particle formation, Atmos. Chem. Phys., 7, 2705-2720, doi:10.5194/acp-72705-2007, 2007.

Pey, J., Rodriguez, S., Querol, X., Alastuey, A., Moreno, T., Putaud, J. P. and Van Dinggenen, R.: Variations of urban aerosols in the western Mediterranean, Atmos. Environ., 42, 9052-9062, doi:10.1016/j.atmosenv.2008.09.049, 2008.

Salma, I., Borsós, T., Weidinger, T., Aalto, P., Hussein, T., Dal Maso, M., and Kulmala, M.: Production, growth and properties of ultrafine atmospheric aerosol particles in an urban environment, Atmos. Chem. Phys., 11, 1339-1353, doi:10.5194/acp-111339-2011, 2011.

Stanier, C., Khlystov, A., and Pandis, S.: Ambient aerosol size distributions and number concentrations measured during the Pitts- 
burgh Air Quality Study (PAQS), Atmos. Environ., 38, 32753284, doi:10.1016/j.atmosenv.2004.03.020, 2004.

Stolzenburg, M. R., McMurry, P. H., Sakurai, H., Smith, J. N., Mauldin III, R. L., Eisele, F. L., and Clement, C. F.: Growth rates of freshly nucleated atmospheric particles in Atlanta, J. Geophys. Res., 110, D22S05, doi:10.1029/2005JD005935, 2005.

Twomey, S.: The influence of Pollution on the Shortwave Albedo of Clouds, J. Atmos. Sci., 34, 1149-1152, 1977.

Wang, M. and Penner, J. E.: Aerosol indirect forcing in a global model with particle nucleation, Atmos. Chem. Phys., 9, 239-260, doi:10.5194/acp-9-239-2009, 2009.

Wichmann, H. E., Spix, C., Tuch, T., Wölke, G., Peters, A., Heinrich, J., Kreyling, W. G., and Heyder, J.: Daily mortality and fine and ultrafine particles in Erfurt, Germany part I: role of particle number and particle mass, Research Report 98, Health Effects Institute, Cambridge, MA, USA, 2000.

Woo, K. S., Chen, D. R., Pui, D. Y. H., and McMurry, P. H.: Measurement of Atlanta aerosol size distribution: observation of ultrafine particle events, Aerosol Sci. Tech., 34, 75-87, doi:10.1080/02786820120056, 2001.

Yli-Juuti, T., Nieminen, T., Hirsikko, A., Aalto, P. P., Asmi, E., Hõrrak, U., Manninen, H. E., Patokoski, J., Dal Maso, M., Petäjä, T., Rinne, J., Kulmala, M., and Riipinen, I.: Growth rate of nucleation mode particles in Hyytiälä during 2003-2009: variation with particle size, season, data analysis method and ambient conditions, Atmos. Chem. Phys., 11, 12865-12886, doi:10.5194/acp-11-12865-2011, 2011.
Young, L.-H., Wang, Y.-T., Hsu, H.-C., Lin, C.-H., Liou, Y.-J, Lai, Y.-C., Lin, Y.-H., Chang, W.-L., Chiang, H.-L., and Cheng, M.T.: Spatiotemporal variability of submicrometer particle number size distribution in an air quality management district, Sci. Total Environ., 425, 135-145, doi:10.1016/j.scitotenv.2012.02.063, 2012.

Young, L.-H., Lee, S.-H., Kanawade, V., Hsiao T.-C., Lee, Y. L., Hwang, B.-F., Liou, Y.-J., Hsu, H.-T., and Tsai, P.-J.: New particle growth and shrinkage observed in subtropical environments, Atmos. Chem. Phys., 13, 547-564, doi:10.5194/acp-13547-2013, 2013.

Yue, D. L., Hu, M., Zhang, R. Y., Wang, Z. B., Zheng, J., Wu, Z. J., Wiedensohler, A., He, L. Y., Huang, X. F., and Zhu, T.: The roles of sulfuric acid in new particle formation and growth in the mega-city of Beijing, Atmos. Chem. Phys., 10, 4953-4960, doi:10.5194/acp-10-4953-2010, 2010.

Zhang, Y. M., Zhang, X. Y., Sun, J. Y., Lin, W. L., Gong, S. L., Shen, X. J., and Yang, S.: Characterization of new particle and secondary aerosol formation during summertime in Beijing, China, Tellus, 63B, 382-394, doi:10.1111/j.1600-0889.2011.00533.x, 2011. 